\title{
A dimensão educativa da equipe de nefrologia na promoção de saúde bucal de crianças e adolescentes portadores de doença renal crônica
}

\author{
Educational dimension of the nephrology team in promoting oral \\ health for chronic renal failure children and adolescents
}

\section{Autores \\ Glaucia Athayde Gonçalves ${ }^{1}$ \\ Carla Martins ${ }^{1}$ \\ Luiz Fernando Rangel \\ Tura $^{2}$ \\ Laura Guimarães \\ Primo $^{1}$ \\ 'Departamento de Odon- topediatria e Ortodontia da Faculdade de Odonto- logia da UFRJ \\ ${ }^{2}$ Departamento de Medicina Preventiva da Faculdade de Medicina da UFRJ}

Data de submissão: 03/04/2009 Data de admição: 17/08/2009

\section{Correspondência para:} Laura Guimarães Primo Rua Voluntários da Pátria, 190/403

Botafogo - Rio de Janeiro -

RJ - CEP: 22.270-010

Telefone/fax: (21) 2286-7408

E-mail:

Iprimo@pobox.com

Declaramos a inexistência de conflitos de interesse.

\section{Resumo}

Introdução: Objetivou-se avaliar a dimensão educativa das percepções e atitudes de médicos, enfermeiros e auxiliares de enfermagem na saúde bucal de crianças e adolescentes portadores de insuficiência renal crônica (IRC) em três hospitais do Rio de Janeiro. Métodos: Realizou-se uma entrevista com perguntas abertas e fechadas com 43 profissionais de saúde. Os dados foram coletados e tabulados no programa SPSS 13.0. Empregou-se o teste Qui-quadrado, com nível de significância estatística $\mathrm{p}<0,05$. Resultados: A média de idade foi 36,5 anos ( $\pm 11,3)$, com $80 \%$ do sexo feminino. A maioria dos médicos $(71,4 \%, \mathrm{n}=10)$ e enfermeiros $(72,4 \%$, $\mathrm{n}=21$ ) acredita que esses pacientes podem ter alguma alteração bucal decorrente da doença, sendo perda de esmalte e descalcificação as mais citadas. Em relação à orientação sobre higiene bucal, pouco mais da metade da amostra respondeu que orienta seus pacientes no sentido de realizar escovação $(72,7 \%, \mathrm{n}=16)$, usar fio dental $(9 \%, \mathrm{n}$ $=2)$, fazer bochecho $(18,1 \%, n=4)$ e limpar a língua $(9 \%, n=2)$. Apenas $9 \%(n=2)$ orientam a higiene após o uso de medicamentos. Quanto à necessidade de cuidados diferenciados para esses pacientes, $65,5 \%$ dos enfermeiros e auxiliares de enfermagem acreditam que estes devam ocorrer. Para a maioria dos médi$\cos (57,1 \%, \mathrm{n}=8)$, não há necessidade de tais cuidados. Apesar disso, 78,6\% (n = 11) dos médicos têm o hábito de encaminhar os pacientes a serviços odontológicos. Conclusões: Diante da metodologia empregada, concluiuse que a maioria dos profissionais de saúde têm algum conhecimento sobre saúde bucal, porém suas atitudes não refletem esse fato.

Palavras-chave: insuficiência renal crônica, educação em odontologia, saúde bucal, criança, adolescente, médicos, enfermeiros.

[J Bras Nefrol 2009;31(3):198-205] OElsevier Editora Ltda.

\section{Abstract}

Objective: To assess the educational dimension through the perceptions and attitudes of physicians, nurses, and nursing assistants in relation to oral health of chronic renal failure (CRF) children and adolescents at three hospitals of Rio de Janeiro. Methods: An interview was conducted using open and closed questions with 43 health professionals. An interview was conducted by 43 health professionals using open and closed questions. Data were collected and uploaded into the SPSS 13.0 program. The chi-square test was used, with statistical significance level of $\mathrm{p}<0.05$. Results: Mean age was $36.5 \pm 11.3$ years, and $80.0 \%$ of the interviewees were female. Most physicians $(71.4 \%, \mathrm{n}=10)$ and nurses $(72.4 \%, \mathrm{n}=21)$ believed $\mathrm{CRF}$ patients could have some degree of oral alteration due to the disease, loss of enamel and decalcification being the most cited. In regard to oral hygiene care, more than half of the interviewees answered that they used to inform their patients about dental brushing $(72.7 \%, \mathrm{n}=16)$, flossing $(9.0 \%$, $\mathrm{n}=2)$, mouth rinsing $(18.1 \%, \mathrm{n}=4)$, and tongue cleaning $(9.0 \%, \mathrm{n}=2)$. Only $9 \%(\mathrm{n}$ $=2$ ) recommended oral hygiene after the use of oral medicines. According to $65.5 \%$ of the nurses and nursing assistants, CRF patients require special care. Most physicians $(57.1 \%, \mathrm{n}=8)$ do not think this is necessary. Nevertheless, $78.6 \%(\mathrm{n}=11)$ of physicians often refer CRF patients to dental services. Conclusions: According to the methodology used, it was concluded that most health care professionals have some knowledge of oral health, but their attitudes do not reflect this fact.

Keywords: chronic renal failure, dental education, oral health, children, adolescent, physicians, nurses. 


\section{INTRODUÇÃO}

Estratégias de prevenção primária em saúde bucal são essenciais em saúde pública, uma vez que doenças bucais, como, por exemplo, a cárie, são comuns em crianças em todo o mundo. ${ }^{1}$ Nesse sentido, a orientação para a higiene bucal, quando iniciada com o paciente infantil, gera resultados positivos não apenas durante a infância, mas também durante a fase adulta.

Contudo, vale ressaltar que, além da importância da saúde bucal para qualquer indivíduo, há doenças que apresentam manifestações bucais específicas, como é o caso da Insuficiência Renal Crônica (IRC). Defeitos de esmalte, atraso na cronologia de erupção e sensação de boca seca são achados comuns. ${ }^{2,3} \mathrm{Na}$ hipótese de xerostomia por período prolongado, há possibilidade de predispor a lesões de cárie e à inflamação gengival e, em alguns casos, levar à dificuldade na fala, mastigação, disfagia e perda do paladar. ${ }^{2}$ O uso de medicamentos - como carbonato de cálcio, sulfato ferroso, vitaminas, antibióticos, anti-hipertensivos e corticosteroides,$-{ }^{3}$ comum entre os pacientes portadores de insuficiência renal crônica, pode provocar efeitos secundários na cavidade bucal. Dentre esses, destacam-se o aparecimento de manchas nos dentes, hipossalivação, cárie e calcificação das partes moles. ${ }^{4,5}$ Além disso, afirma-se na literatura que a higiene bucal de indivíduos em tratamento de hemodiálise pode se apresentar deficiente. ${ }^{6}$

Considerando que a equipe que atua nos serviços de nefrologia, principalmente nos centros de diálise, mantém contato frequente e próximo com os pacientes portadores de IRC, há maior oportunidade de que esses profissionais detectem precocemente o desenvolvimento de problemas odontológicos e aconselhem sobre a importância da prevenção. Eles podem, ain$\mathrm{da}$, perceber os primeiros sinais de alterações bucais e encaminhar para tratamento dentário, quando necessário.

$\mathrm{Na}$ literatura consultada, não foram encontrados trabalhos abordando a atuação da equipe de saúde com relação à saúde bucal de pacientes portadores de IRC. Desse modo, este estudo torna-se relevante ao avaliar a dimensão educativa por meio das percepções e atitudes de médicos, enfermeiros e auxiliares de enfermagem na saúde bucal de crianças e adolescentes portadores dessa patologia em três hospitais da cidade do Rio de Janeiro.

\section{Métodos}

A amostra foi constituída pela totalidade dos médicos, enfermeiros e auxiliares de enfermagem que compunham a equipe de nefropediatria de três hospitais da cidade do Rio de Janeiro. Os dados foram coletados por meio de entrevistas conduzidas pela pesquisadora responsável pelo estudo. O roteiro foi um questionário composto de vinte questões abertas e dez fechadas (Apêndice 1). Todas as entrevistas foram realizadas dentro do prazo máximo de duas semanas em cada hospital e tiveram por finalidade avaliar o conhecimento dos profissionais quanto às manifestações bucais da doença renal e quanto ao uso de medicamentos para essas doenças, suas percepções acerca da saúde bucal dos pacientes, assim como suas atitudes de encaminhar o paciente ao serviço odontológico.

O roteiro da entrevista foi pré-testado com dez profissionais da área de saúde, dentre eles médicos e auxiliares de enfermagem, em outro hospital da cidade do Rio de Janeiro, a fim de verificar a clareza, a coerência e a objetividade das perguntas. A pesquisa contou com a aprovação do Comitê de Ética em Pesquisa local e todos os profissionais de saúde que participaram do estudo assinaram o Termo de Consentimento Livre e Esclarecido.

Com vistas à análise estatística, as perguntas abertas foram categorizadas por aproximação semântica, e um mesmo sujeito da amostra pode ter dado mais de uma resposta à mesma pergunta. Por não ter havido diferença estatística entre as respostas de enfermeiros e auxiliares de enfermagem, na maior parte da análise dos resultados ambas as categorias foram agrupadas em um único bloco. Os resultados das perguntas abertas e fechadas foram inseridos no programa SPSS 13.0, e, para avaliação dos resultados, empregou-se o Teste Qui-quadrado, estabelecendo-se o nível de significância estatística $\mathrm{p}<0,05$.

\section{Resultados}

A amostra foi composta de 43 profissionais de saúde: 14 médicos, 11 enfermeiros e 18 auxiliares de enfermagem, das redes pública e privada. O gênero feminino compôs $80 \%$ da amostra e a média de idade do total da amostra foi de 36,5 ( $\pm 11,30)$ anos. A distribuição dos profissionais em cada hospital se mostrou homogênea, não havendo diferença estatística entre eles. Dos entrevistados, 65,1\% ( $\mathrm{n}=29)$ acompanham pacientes com IRC há menos de dez anos. No grupo dos médicos, 42,9\% $(\mathrm{n}=6)$ eram nefropediatras; $28,6 \%(\mathrm{n}=4)$, pediatras; e $28,6 \%(n=4)$, nefrologistas. 
A maioria dos médicos ( $\mathrm{n}=10,71,4 \%)$ respondeu acreditar que os pacientes portadores de IRC podem ter alguma alteração bucal decorrente da doença, enquanto $28,6 \%(\mathrm{n}=4)$ responderam desconhecer esse fato. Vinte e um enfermeiros e auxiliares de enfermagem $(72,4 \%)$ responderam afirmativamente a essa pergunta, enquanto $13,8 \%$ $(\mathrm{n}=4)$ afirmaram não haver relação da IRC com manifestações bucais e outros $13,8 \%$ disseram não saber a resposta.

As principais alterações bucais citadas pelos sujeitos são apresentadas na Figura 1. Salienta-se que dois auxiliares de enfermagem $(33,3 \%)$ e um médico $(21,4 \%)$ da amostra não souberam responder a essa pergunta. Entre os médicos, $60 \%(\mathrm{n}=9)$ desconhecem tais alterações. Trinta $(66,6 \%)$ dos 43 profissionais da pesquisa relataram ter pacientes necessitando de cuidados odontológicos. Desses, apenas $35 \%(\mathrm{n}=11)$ os encaminham ao serviço odontológico.

Quando médicos e profissionais de enfermagem foram questionados se já haviam orientado sobre algum cuidado de higiene bucal, $22(51,1 \%)$ responderam que "sim". Desses, $72,7 \%(\mathrm{n}=16)$ orientam para escovação, $9 \%(\mathrm{n}=2)$ para uso de fio dental, $18,1 \%(\mathrm{n}=4)$ para realização de bochecho e $9 \%$ $(\mathrm{n}=2)$ para limpeza da língua. A higiene após o uso de medicamentos é aconselhada por $9 \%(\mathrm{n}=2)$ desses profissionais. A relação foi estatisticamente significativa entre as respostas de médicos e profissionais de enfermagem quando questionados sobre o fato de a saúde bucal agravar a saúde geral e se medicações interferem na cavidade bucal.

Em relação aos medicamentos, 42,9\% $(\mathrm{n}=6)$ dos médicos acreditam que sua utilização por esses pacientes pode alterar a cavidade bucal. Cinco $(83,3 \%)$ citaram o sulfato ferroso, por manchar os dentes, e um $(16,7 \%)$ os xaropes, por conterem açúcar. Contudo, dos vinte (69\%) enfermeiros que responderam afirmativamente a essa questão, 14 $(70 \%)$ afirmaram que os medicamentos podem causar dentes amarelados e/ou enfraquecidos, enquanto três $(15 \%)$ apontaram mancha por sulfato ferroso e outros três $(15 \%)$ não sabiam dizer a alteração decorrente do uso de medicamentos. A diferença entre a opinião dos médicos e enfermeiros mostrou diferença significativa nesse item $(\mathrm{p}<0,05)$.

Dentre os profissionais de saúde que acreditaram que os medicamentos poderiam alterar a cavidade bucal, $83,3 \%(\mathrm{n}=5)$ dos médicos e $30 \%$ $(n=6)$ dos enfermeiros e auxiliares de enfermagem informavam essa ocorrência aos responsáveis.

Ao serem indagados sobre o critério adotado para a prescrição de medicamentos para crianças e adolescentes com IRC, $50 \%(\mathrm{n}=7)$ dos médicos responderam ser o quadro clínico do paciente, enquanto $42,9 \%(\mathrm{n}=6)$ afirmaram ser o fator econômico o principal critério. Um médico $(7,1 \%)$ considerou a idade o principal critério.

Com relação ao fato de a saúde bucal poder agravar a saúde geral dos pacientes com IRC, 85,7\% $(\mathrm{n}=12)$ dos médicos e $75,9 \%(\mathrm{n}=22)$ dos enfermeiros

Figura 1. Frequência das manifestações bucais decorrentes da IRC citadas pelos sujeitos da amostra.

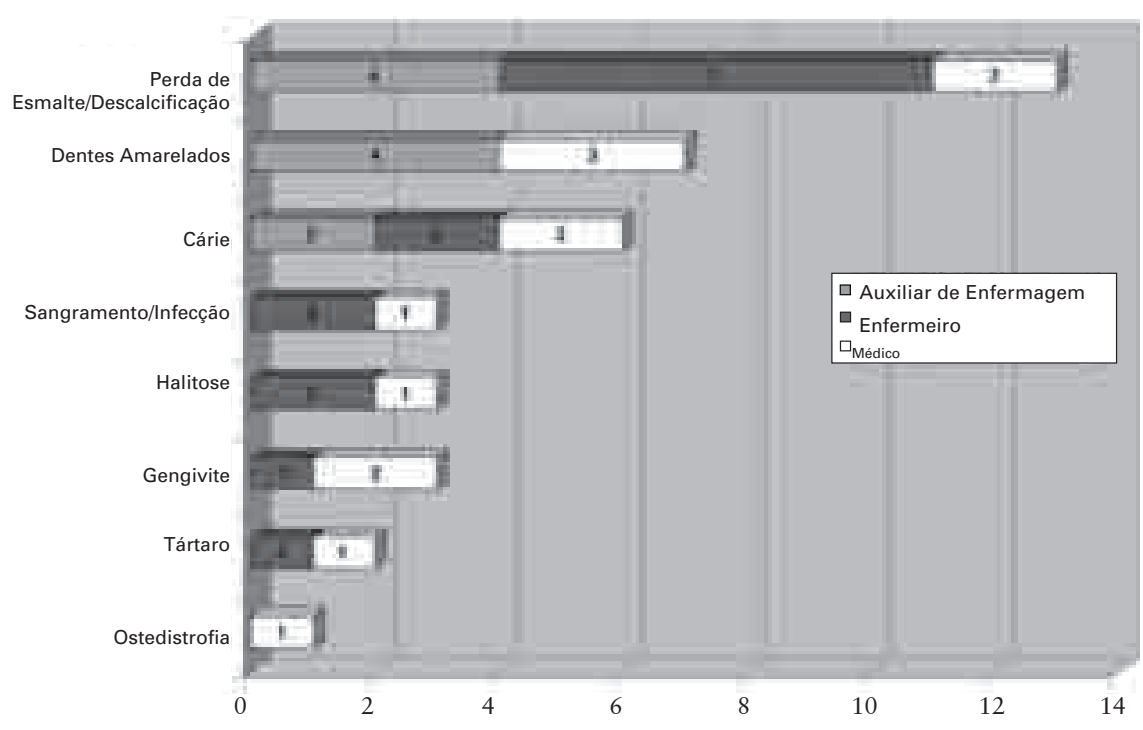


e auxiliares de enfermagem responderam afirmativamente, sendo essa relação estatisticamente significativa $(\mathrm{p}<0,05)$.

Do total de enfermeiros e auxiliares de enfermagem, 65,5\% ( $\mathrm{n}=19)$ acreditam que os cuidados com a saúde bucal dos pacientes com IRC devem ser diferentes dos pacientes saudáveis. No entanto, $57,1 \%(\mathrm{n}=8)$ dos médicos não consideram necessário esse cuidado especial e somente um $(7,1 \%)$ citou o risco de endocardite bacteriana como motivo para a realização de melhor higiene bucal.

Desse modo, quando questionados sobre qual profissional deve orientar o paciente com IRC em relação à higiene bucal, a especialidade mais citada pela amostra foi o dentista ( $\mathrm{n}=19,26 \%$ ), seguido do enfermeiro $(\mathrm{n}=17,23,2 \%)$ e do nefrologista $(\mathrm{n}=16,21,9 \%)$. Outros profissionais também citados foram o pediatra $(\mathrm{n}=12,16,4 \%)$ e o auxiliar de enfermagem $(\mathrm{n}=7,9,58 \%)$. Quando indagados se já haviam recomendado algum cuidado com a higiene bucal, $78 \%(\mathrm{n}=11)$ dos médicos e $37,9 \%$ ( $\mathrm{n}=11)$ dos enfermeiros e auxiliares de enfermagem responderam afirmativamente, com relação estatisticamente positiva $(\mathrm{p}<0,05)$.

Com relação à frequência ideal das visitas dos pacientes portadores de IRC ao dentista, sete médicos $(50 \%)$ e a maioria dos enfermeiros e auxiliares de enfermagem $(\mathrm{n}=22,75,9 \%)$ disseram ser de seis em seis meses. Vale ressaltar que 78,5\% ( $\mathrm{n}=11)$ dos médicos e $55,1 \%(\mathrm{n}=16)$ enfermeiros e auxiliares de enfermagem reconhecem que a fonte de infecção na cavidade bucal pode agravar o estado de saúde geral do paciente com IRC. No entanto, apenas $17,2 \%(n=-5)$ de enfermeiros e auxiliares de enfermagem costumam encaminhar o paciente a serviços odontológicos, enquanto 78,5\% ( $\mathrm{n}=11)$ dos médicos têm esse hábito. Contudo, apenas $7,1 \%(\mathrm{n}=1)$ dos médicos o fazem como rotina, sem que o paciente apresente qualquer sinal ou sintoma bucal.

Ao serem questionados se a dieta do paciente com IRC pode influenciar o aparecimento de cáries, $41,9 \%(\mathrm{n}=18)$ do total da amostra responderam que $\operatorname{sim}, 32,5 \%(\mathrm{n}=14)$ responderam negativamente e $25,6 \%(n=11)$ não souberam responder à pergunta.

\section{Dıscussão}

Considerando que a equipe presente nos serviços de nefrologia tem maior contato com os pacientes portadores da patologia em questão, torna-se interessante abordar o nível de conhecimento desses profissionais e suas atitudes em relação a esses pacientes.
Em um estudo realizado por Tsamtsouris e Gravis (1990) com pediatras, observou-se que apenas $13,4 \%$ consideravam seus conhecimentos de saúde oral excelentes e $33,4 \%$ reconheciam a necessidade de melhorá-los. A maioria dos trabalhos que tratam das percepções e atitudes dos médicos é realizada com pediatras, porém não se encontrou, na literatura consultada, qualquer pesquisa com nefrologistas e nefropediatras.

Embora a equipe de nefrologia seja composta por médicos, enfermeiros, auxiliares de enfermagem, nutricionistas e fisioterapeutas, as duas últimas classes de profissionais aparecem em número reduzido. Tal fato poderia gerar confusão na análise estatística. Além disso, o contato dessas especialidades com o paciente é menor. Por isso, optou-se por não incluí-los no estudo.

A maior parte dos médicos, enfermeiros e auxiliares de enfermagem afirmou que existem alterações bucais relacionadas à IRC. Parte das manifestações bucais mais comuns nos pacientes foi identificada por alguns profissionais. Entretanto, eles ainda necessitam de maior conhecimento para constatar outras alterações, como estomatite urêmica, equimoses, inflamação gengival, perda de inserção dentária e atraso na erupção dentária. A partir de então, espera-se que a condição de saúde bucal dos pacientes melhore substancialmente, diminuindo o número de lesões de cárie e de doença periodontal e reduzindo significativamente o risco de infecção sistêmica de origem dentária, tornandoos aptos a receber transplante renal. ${ }^{6,8}$

Mesmo que mais da metade do total da amostra reconheça que há pacientes que necessitam de tratamento odontológico, poucos os encaminham a esse serviço, ao contrário do que foi encontrado por Cavalcanti et al. (1999), em cujo estudo 89\% dos pediatras encaminhavam seus pacientes ao odontopediatra. Os médicos entrevistados relataram que o não encaminhamento de crianças com IRC decorria da ausência de disponibilidade de serviços odontológicos, realidade semelhante à do levantamento realizado por Lewis et al. (2000) nos Estados Unidos, onde mais de $50 \%$ dos pediatras encontraram dificuldades para encaminhar pacientes que não tinham seguro odontológico ao dentista. Somando-se a isso, a rotina das crianças em hemodiálise ocupa boa parte do tempo que poderia ser destinada à visita ao dentista. Dessa forma, o preparo da equipe de nefrologia se torna extremamente importante, uma vez que eles são o principal elo no fornecimento de informações aos responsáveis e aos pais e terão várias oportunidades para fazê-lo. 
Algumas alterações dentárias causadas por medicamentos, como pigmentação extrínseca por sulfato ferroso ou lesões de cárie pelo uso frequente de medicamentos líquidos orais, poderiam ser evitadas ou minimizadas realizando-se a lavagem da boca após a ingestão dos remédios e profilaxia profissional periódica no dentista. ${ }^{11,12}$ Entretanto, poucos profissionais da amostra conheciam esse fato. Vale salientar também que alguns medicamentos para pacientes com IRC apresentam alto custo. Desse modo, muitas vezes as famílias optam por soluções líquidas, mais baratas, que usualmente contêm alto teor de açúcar. ${ }^{12}$

Os pacientes com doença renal crônica têm orientações dietéticas de acordo com a taxa de filtração glomerular e o tipo de tratamento realizado. Todos são encorajados a fazer ingestão de grande quantidade de carboidratos, preferencialmente os complexos, e a restringirem o consumo de proteínas. ${ }^{13}$ Vale lembrar que os carboidratos simples são permitidos e, caso a higiene bucal não seja realizada, o risco de aparecimento de cárie aumentará ainda mais se esse hábito for perpetuado após o transplante. A maioria dos profissionais entrevistados não soube ou não associou a dieta ao aparecimento de cárie, evidenciando conhecimento inadequado sobre o tema.

Embora muitos acreditem que seja responsabilidade do cirurgião-dentista orientar quanto à higiene bucal, Lewis et al. (2000) concluíram que os médicos acreditam desempenhar papel importante na promoção de saúde oral. Em estudo realizado por Pandolfi et al. (2001), concluiu-se que o pediatra mostra grande interesse quanto à saúde bucal de seus pacientes, reforçando a necessidade da interação pediatra-odontopediatra. No caso da IRC, seria de grande valia que os médicos recebessem orientação e motivação dentro dos serviços de nefrologia, visto que o comprometimento bucal pode afetar a saúde geral desses pacientes. ${ }^{15} \mathrm{O}$ risco aumentado de infecções associadas com bacteremia odontogênica deve chamar a atenção para a redução de carga bacteriana oral, obtida por meio de dentes livres de biofilme e sem inflamação gengival.

Alguns profissionais integrantes da pesquisa orientam para a realização de higiene bucal, para o uso de soluções fluoretadas e/ou antissépticas para bochecho. Salienta-se que tal indicação deve ser realizada cuidadosamente como prescrição nos casos de pacientes portadores de IRC, uma vez que a ingestão indevida desses produtos trará problemas para o paciente, devido à incapacidade do rim de filtrar essas soluções. ${ }^{11}$
Percebe-se a necessidade de estabelecer um programa de capacitação em saúde bucal aos profissionais que acompanham pacientes com IRC, por meio de palestras, cursos de extensão e distribuição de material informativo nos hospitais e serviços de nefrologia. $\mathrm{O}$ ideal seria que o cirurgião-dentista estivesse inserido na equipe de atendimento aos pacientes portadores de IRC de cada hospital. No entanto, enquanto isso não é viável, faz-se necessária a participação ativa dos demais profissionais, enfermeiros, médicos e nutricionistas, entre outros, na prevenção em saúde bucal, detectando os primeiros sinais de alterações bucais e, portanto, contribuindo para melhorar a qualidade de vida desses pacientes.

Uma vez que a equipe conheça e saiba identificar as manifestações bucais da IRC e reconheça a importância dos cuidados para que sejam evitadas complicações de saúde geral nesses pacientes, ela se tornará mais consciente e poderá atuar em conjunto com o dentista para promover a qualidade de vida dessas pessoas.

\section{Conclusão}

Diante da amostra pesquisada, pode-se concluir que a dimensão educativa da equipe de saúde na promoção de saúde bucal de crianças e adolescentes portadores de IRC é pequena. Apesar do interesse da equipe pela saúde bucal dos pacientes, é possível observar, por suas percepções, que existe pouco conhecimento sobre o tema. Há necessidade ainda maior de informação e motivação dos profissionais que lidam com pacientes renais, com o objetivo de tornar eficaz a prevenção em saúde bucal.

\section{Agradecimentos}

Gostaríamos de agradecer ao Prof. Ronir Raggio Luiz, pelo apoio estatístico a este trabalho.

\section{ReferênCIAS}

1. Giuseppe GD, Nobile CGA, Marinelli A, Angelillo IF. Knowledge, Attitude and Practices of Pediatricians Regarding the Prevention of Oral Diseases in Italy. BMC Public Health 2006; 6:176.

2. Kho HS, Lee SW, Chung SC, Kim YKl. Oral Manifestations and Salivary Flow Rate, ph, and Buffer Capacity in Patients with End-Stage Renal Disease Undergoing Hemodialysis. Oral Surg Oral Med Oral Pathol Oral Radiol Endod 1999; 88:316-9.

3. Nunn JH, Ng SK, Sharkey I, Coulthard M. The Dental Implications of Chronic Use of Acidic Medicines in Medically Compromised Children. Pharm World Sci 2001; 23:118-9.

4. Jacobsen PL, Chávez EM. Clinical Management of the Dental Patient Taking Multiple Drugs. J Contemp Dental Pract 2005; 6:144-51. 
5. Leite CG, Monção SMM. Rotinas do serviço de pediatria do Hospital dos Servidores do Estado. 6 ed. revista e ampliada. Rio de Janeiro: Revinter, 1998, 11:400-8.

6. Naugle K, Darby ML, Bauman BD, Lineberger LT, Powers R. The Oral Health Status of Individuals on Renal Dialysis. Ann Periodontol 1998; 3:197-205.

7. Tsamtsouris A, Gravis V. Survey of Pediatrician's Attitudes Towards Pediatric Dental Health. J Pedod 1990; 14:152-7.

8. Marakoglu I, Gursoy UK, Demirer S, Sezer H. Periodontal Status of Chronic Renal Failure Patients Receiving Hemodialysis. Yonsei Med J 2003; 44:648-52.

9. Cavalcanti AL, Albuquerque ATDL, Santana MA. Conhecimentos e atitudes do médico pediatra das cidades de João Pessoa e Campina Grande com relação à saúde bucal. Pediatr Mod 1999; 35:411-4.

10. Lewis CW, Grossman DC, Domoto PK, Deyo RA. The Role of the Pediatrician in the Oral Health of Children: a national survey. Pediatrics 2000; 106:E84.
11. Nunn JH, Ng SK, Sharkey I, Coulthard M. The Dental Implications of Chronic Use of Acidic Medicines in Medically Compromised Children. Pharm World Sci 2001; 23:118-9.

12. Maguire A, Rugg-Gunn AJ. Prevalence of Long-Term Use of Liquid Oral Medicines by Children in the Northern Region. England. Community Dent Health 1994; 11:91-6.

13. Levy HM. Dental Considerations for the Patient Receiving Dialysis for Renal Failure. Spec Care Dentist 1988; 8:34-6.

14. Pandolfi M, Maeda FH, Torres PL, Gomes LP. Perfil de médicos pediatras do estado do Espírito Santo diante da saúde bucal. UFES Rev Odontol 2001; 3:80-7.

15. Roberts GJ. Dentists are Innocent! Everyday Bacteraemia is the Real Culprit: a Review and Assessment of the Evidence that Dental Surgical Procedures are a Principal Cause of Bacterial Endocarditis in Children. Pediatr Cardiol 1999; 20:317-25.

\section{APÊNDICE 1 RoteIRO de ENTREVISTA PARA OS MÉdICOS E ENFERMEIROS DE PACIENTES COM IRC:}

Data da entrevista:

Idade:

Especialidade: ( ) Nefrologia

( ) Urologia
Número de identificação

Tempo de formado:

( ) Pediatria

( ) Endocrionologia

( ) Nefropediatria

( ) Auxiliar de Enfermagem

( ) Outros

1. Onde trabalha

( ) Serviço público e consultório particular

( ) Serviço público

( ) Consultório particular

( ) Outros

2. Há quanto tempo acompanha pacientes com IRC:
( )menos de 5 anos
( )de 5 e 10 anos
( )de 10 a 15 anos
( )mais de 15 anos

3. Na sua opinião, os pacientes podem ter alguma complicação bucal decorrente da IRC?
( ) Sim
( )Não
( )Não sei
( ) Às vezes

4. Quais?

5. Você costuma informar sobre alterações bucais aos responsáveis ou pacientes com IRC?
( ) Sim
( )Não
( )Às vezes

6. Quais?

7. Existem critérios que influenciam a prescrição de medicamentos nos pacientes com IRC?
( ) Sim
( )Não
( )Às vezes 
Continuação Apêndice 1

8. Que critérios são esses?
( )econômicos
( )idade do paciente
( )quadro clínico/sintomas
( )gravidade da doença
( )outros

9. Quais os medicamentos mais usualmente prescritos por você para cada tipo de tratamento?

\begin{tabular}{|l|l|l|l|}
\hline Medicamento & Tratamento Conservador & Diálise Peritoneal & Hemodiálise \\
\hline Carbonato de cálcio & & & \\
\hline Calcitrol & & & \\
\hline Hemax & & & \\
\hline Renagel & & & \\
\hline Nuripurum & & & \\
\hline Vitaminas do Complexo B & & & \\
\hline Vitamina C & & & \\
\hline Anti-hipertensivo & & & \\
\hline Sulfato Ferroso & & & \\
\hline Outros: &
\end{tabular}

10. Na sua opinião, os pacientes podem ter alguma complicação bucal decorrente do uso destes medicamentos?
( ) Sim
( )Não
( )Não sei
( )Às vezes

11. Se positivo, quais?

Carbonato de cálcio

Hemax

Complexo B

Anti-hipertensivo

Vitaminas do complexo C

Calcitrol

Renagel

Sulfato ferroso

Vitaminas do complexo B

Outros

12. Essas complicações são informadas ao paciente/responsável?
( ) Sim
( )Não
( )Às vezes

13. Já recomendou algum cuidado de higiene bucal ao paciente com IRC?
( ) Sim
( )Não
( ) Às vezes

14. Se positivo, quais?

15. Na sua opinião, qual profissional deve orientar o paciente/responsável portador de IRC quanto aos cuidados de saúde bucal?
( )Pediatra
( )Nefropediatra
( )Dentista
( )Nefrologista
( ) Enfermeiro
( )Auxiliar de enfermagem
( )Odontopediatra
( )Outros

16. Por quê?

17. Na sua opinião, qual a frequência ideal para as visitas do paciente IRC ao dentista?
( )Anual
( )A cada seis meses
( )A cada 3 meses
( )Mensal
( )Semanal
( )Não sabe

18. No presente momento, você possui algum paciente com IRC necessitando de cuidados odontológicos?
( ) Sim
( )Não
( )Não sei 
19. Qual cuidado?

20. Você tem como hábito encaminhar pacientes para serviço odontológico?
( ) Sim
( )Não

21. Em quais circunstâncias?

22. Para qual serviço?

23. Acredita que a saúde bucal deficiente possa agravar o estado de saúde geral do paciente IRC?
( ) Sim
( )Não
( ) Às vezes

24. Por quê?

25. Os cuidados bucais de higiene do paciente IRC devem ser iguais aos cuidados bucais de uma criança saudável?
( ) Sim
( )Não
( )Não sei

26. Por quê?

27. Que complicações bucais podem advir da IRC:
( )Xerostomia/sensação de boca seca
( )Sangramento gengival
( )Cálculo/tártaro
( )Lesão ou ferida na cavidade bucal
( )Alteração do paladar
( )Perda do paladar
( )Hálito urêmico
( )Cárie
( )Dificuldade mastigatória
( )Não sei
( )Outras:

28. O paciente renal possui restrição em relação à dieta?
( ) Sim
( )Não

29. Caso positivo, quais restrições?

30. Esta dieta pode influenciar o aparecimento de tártaro ou cárie dental?
( ) Sim
( ) Não

Observações: 